\title{
GRANULOMA OF THE LACRIMAL SAC SIMULATING A TUMOUR* WITH A NOTE ON THE USEFULNESS OF FROZEN SECTIONS
}

\author{
BY \\ L. MEYERSON AND J. C. E. KAUFMANN \\ From the Johannesburg General Hospital and the Neuropathology Department, South African \\ Institute for Medical Research
}

SEVERAL reasons induced us to publish the following case: granulomata and neoplasms of the lacrimal sac are rare, there is a likelihood of an intermittent ball-valve type of obstruction having occurred, concretions without demonstrable Streptothrix infection were associated with the granuloma, and frozen sections were of help in diagnosis and thus in the preservation of the lacrimal sac.

\section{Case Report}

A white male aged 37 years was referred to one of us (L.M.) by a general practitioner on August 3,1959, because of a painful lump on the right side of the nose of 10 days' duration. The condition had been treated as a dacryocystitis with antibiotics by mouth, oxytetracycline eye ointment, and infra-red rays for 4 days. In spite of the treatment the lump had grown larger. The right eye had been "watering" intermittently for the past year and about 10 days before examination the patient had noticed slight bleeding from the right nostril. His general health had been good except for an attack of sinusitis one year before. The family history was not significant. The patient wore spectacles with a myopic correction.

Examination.-A hard fixed mass about $1 \mathrm{~cm}$. in diameter was present in the region of the right naso-lacrimal sac. Pressure over this mass did not cause regurgitation of pus or fluid through the lacrimal puncta, which were normal in size and position. Also on syringing there was no obstruction to the lacrimal passages and neither pus nor fluid were returned through the puncta.

A postero-anterior radiograph of the skull revealed no bony abnormality or other pathology. Instillation of water-soluble iodine showed that the lacrimal passages were patent but incompletely filled (Fig. 1, opposite).

Diagnosis.-A mass in the naso-lacrimal sac, probably carcinoma.

Operation.-Surgery was performed under hypotensive anaesthesia. The usual incision was made along the anterior lacrimal crest and a greatly distended lacrimal sac was exposed. From this a glairy fluid was withdrawn through a large-bore needle, and this decreased the distension. When the medial wall of the sac was opened a white mass was found occupying about one-quarter of the lumen. A part of this mass was excised and frozen sections were cut from it. These revealed non-specific inflammatory tissue and the remainder of the mass was then excised. Next the naso-lacrimal duct was probed and a granular sensation was obtained. Finally the sac was sutured with chromic catgut. 
FIG. 1.-Radio-opaque dye incompletely filling the right nasolacrimal apparatus.

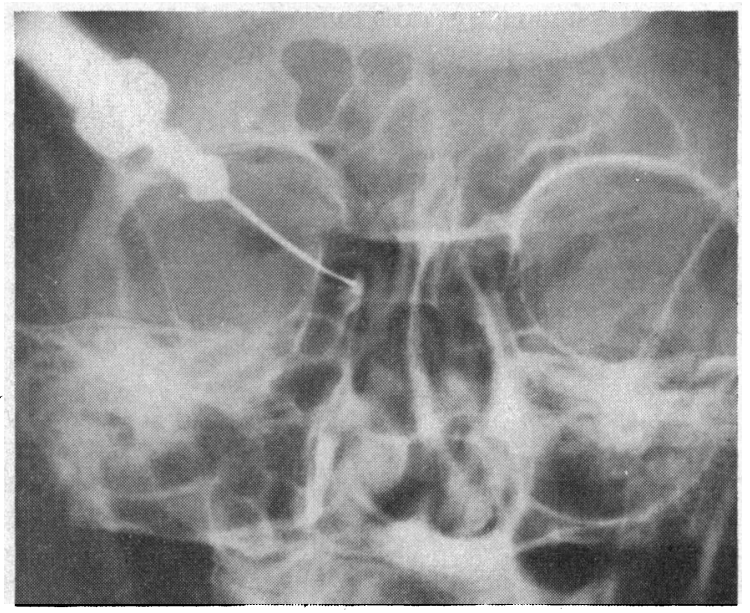

Result.-The patient's post-operative progress was uneventful and there had been no recurrence of symptoms up to the time of re-examination on 3, November, 1960, when he returned for testing for new spectacles. There was no swelling at the operation site and only a healthy scar remained.

Pathological Findings.-Paraffin sections prepared from the remainder of the mass showed fragments of chronically inflamed connective tissue and one large and several small bodies having the appearances of concretions. The inflammatory cells comprised aggregates of lymphocytes, plasma cells, and some histiocytes, and in places a sprinkling of polymorphonuclear cells. The concretions were formed of dense, fairly homogeneous, amorphous material containing a few vacuoles, and had a laminated and scalloped edge which was intensely basophilic because of calcification (Fig. 2).

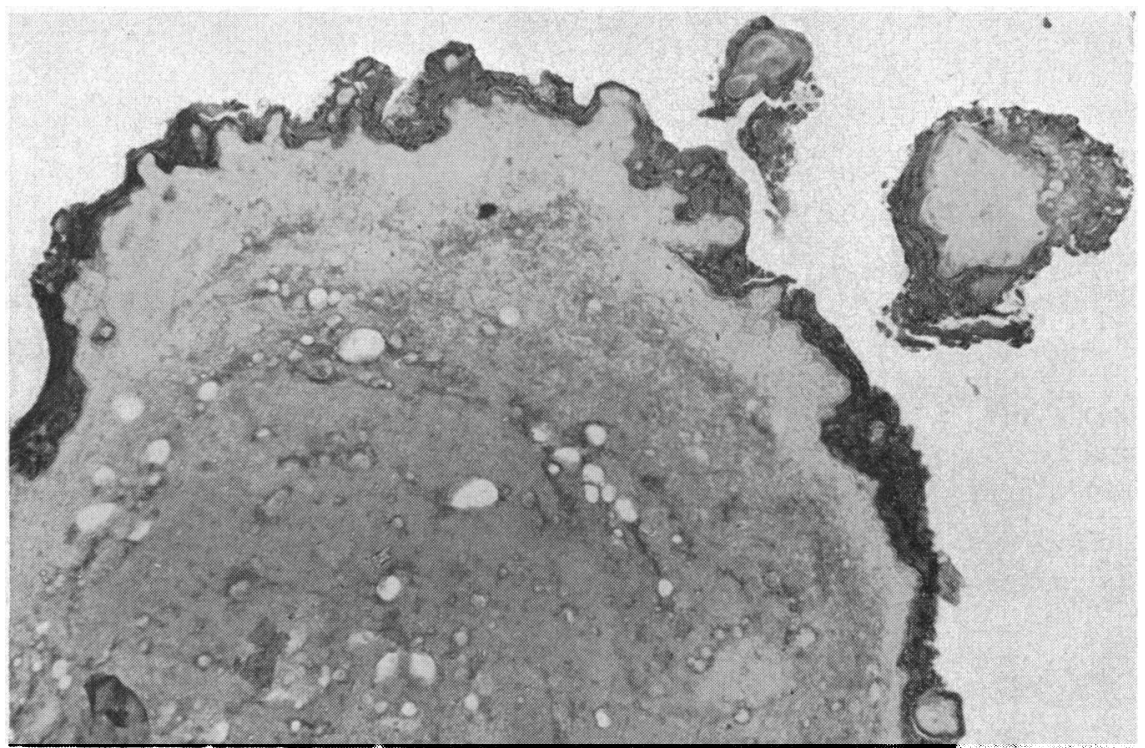

Fig. 2.-Concretions. Note the laminated and scalloped edges staining intensely with haematoxylin and the vacuoles in the largest concretion. Haematoxylin and eosin. $\times 90$. $10^{*}$ 
Irregular and elongated spaces in the largest fragment were filled with material that was periodic-acid Schiff positive even after exposure to the action of amylase (Figs 3 and 4); this material was probably mucus.

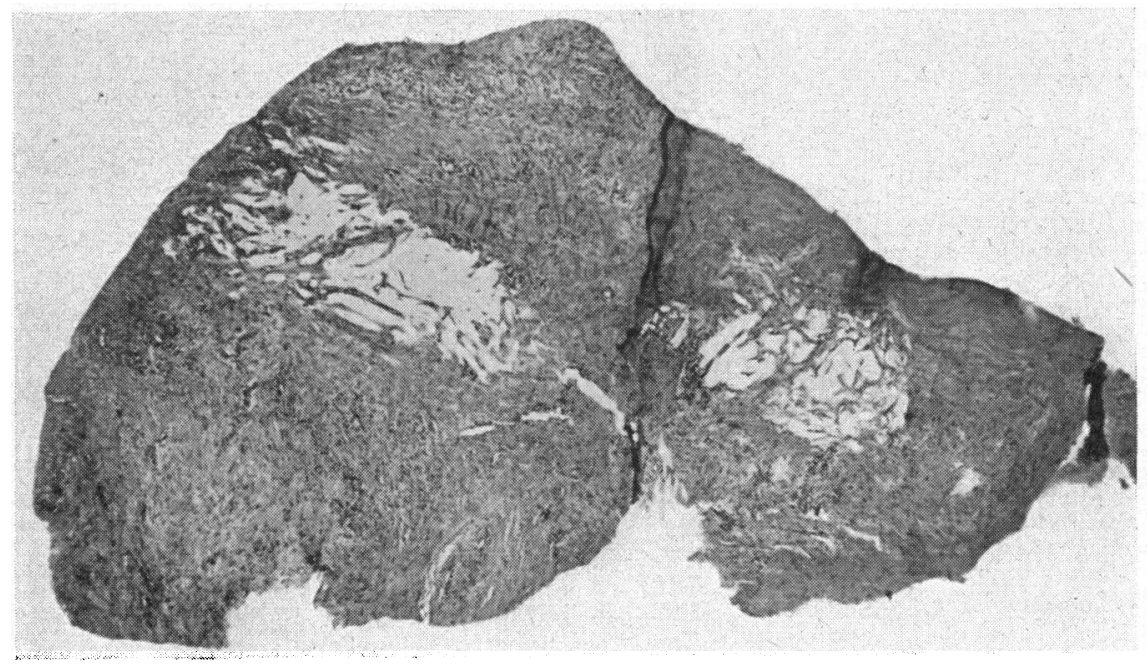

FIG. 3.-Low-power view, showing spaces in one fragment and inflam-

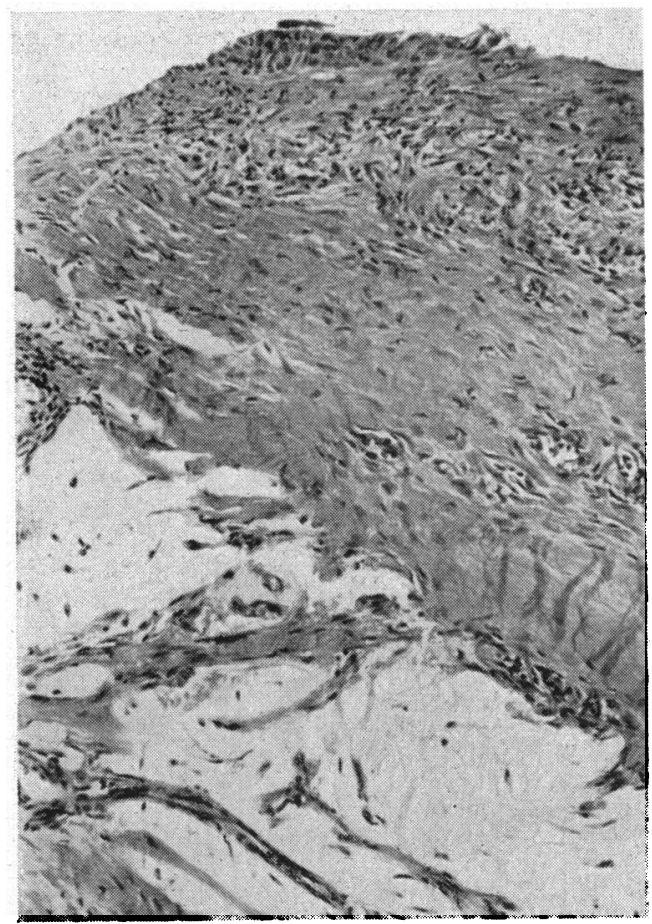
matory cell infiltrate. Haematoxylin and eosin. $\quad \times 36$.

FIG. 4.- Higher power of Fig. 3. Note material in spaces and fragment of stratified squamous epithelium on surface. Haematoxylin and eosin. $\times 133$. 
Mucus could have been secreted by local mucous cells scattered in the epithelium of the naso-lacrimal sac (Seidel, 1931; Lauber, 1936; Friedenwald and others, 1952) which we believe to be the case; or by mucous cells higher up in the conjunctiva; or by glands in the submucosa of the naso-lacrimal sac. The last possibility is unlikely, because such glands occur in only about 8 per cent. of cases (Lauber, 1936) and do not, in fact, seem to be mucous glands at all. It is true that, when describing the structure of the lacrimal sac, Wolff (1954) asserted that "mucous glands have also been described", but other authorities had previously stated that the glands were serous or albuminous glands resembling sweat or Krause's glands, and tubular or tubulo-alveolar in shape (Seidel, 1931; Lauber, 1936; Friedenwald and others, 1952).

The same largest fragment of tissue also bore a short length of stratified squamous epithelium on the surface (Fig. 4), while elsewhere the covering epithelium consisted of two layers of epithelial cells, that towards the lumen being columnar in shape. The normal epithelium lining the sac is two-layered, the inner layer (towards the lumen) being formed of tall columnar cells which become smaller and pointed at their bases so that the second layer is found between the pointed ends (Lauber, 1936). Sometimes, in the adult, the tall columnar cells are ciliated and, as indicated above, goblet cells may be found. Maximow and Bloom (1957) differ from other authorities in stating that the sac is lined by a pseudo-stratified tall columnar epithelium. In our case inflammatory metaplasia seems to have been the cause of the stratified squamous epithelium and this has already been observed at this site (Ashton, Choyce, and Fison, 1951).

Near the surface of one fragment there was an elongated space (Fig. 5) lined by a flattened epithelium from one to several layers thick. The space may have been only a fold on the surface; the question of a possible diverticulum was raised but it could not be answered because of the absence of the space from deeper sections cut from the block.

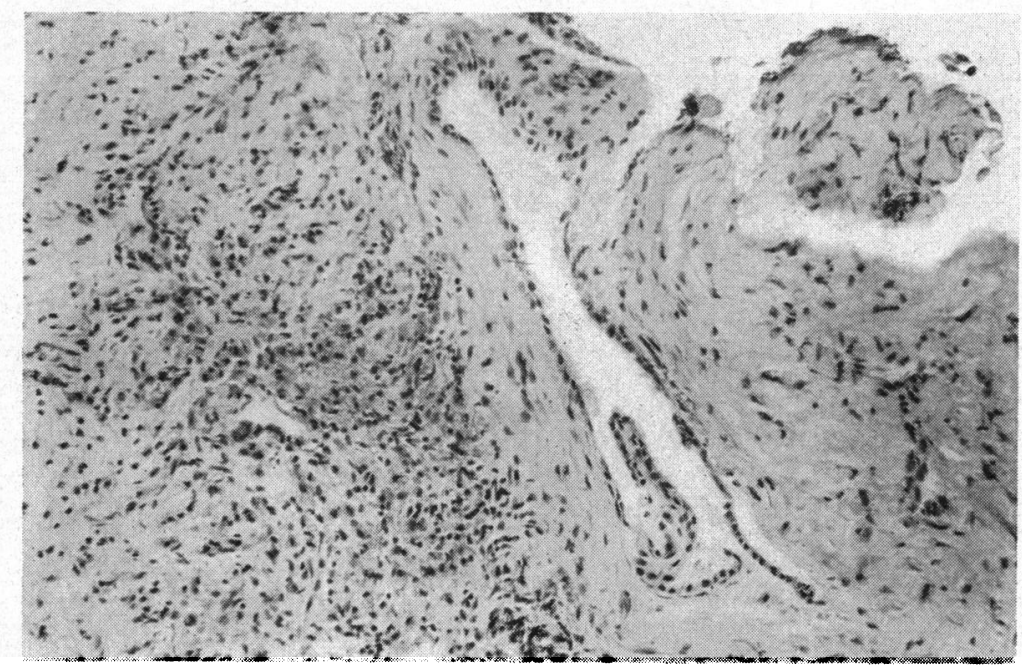

Fig. 5.-Elongated space near the surface of one fragment which is lined by an epithelium from one to several layers thick. Haematoxylin and eosin. $\times 133$.

\section{Discussion}

Neoplasms and Granulomata of the Lacrimal Sac.-An analysis of 117 cases reported in the literature since 1772 (Duke-Elder, 1952a) indicates that 
malignant neoplasms, particularly carcinomata, are commoner than granulomata. Ashton, Choyce, and Fison (1951) suggested that the terms papilloma, carcinoma, and epithelioma used in the earlier literature refer to different stages in the evolution of the same growth (which is closely similar to or identical with the so-called transitional cell papilloma of the nose and paranasal sinuses) so that the actual number of carcinomata may exceed the 39 given in the Table. Several neoplasms have been reported since 1952, one of these being an angioma which caused tears of blood. Jones (1956) added six other neoplasms to the list, including an example of Kaposi's angiosarcoma.

TABLE

CASES REPORTED IN THE LITERATURE SINCE 1772 (DUKE-ELDER, 1952a)

\begin{tabular}{|c|c|c|}
\hline \multicolumn{2}{|c|}{ Type of Tumour } & \multirow{2}{*}{$\frac{\text { No. of Cases }}{26}$} \\
\hline Pseudo-tumours & Granulomata & \\
\hline Epithelial Tumours & $\begin{array}{l}\text { Papillomata } \\
\text { Adenomata } \\
\text { Pleomorphic adenoma } \\
\text { Carcinomata }\end{array}$ & $\begin{array}{r}11 \\
2 \\
2 \\
39\end{array}$ \\
\hline Mesenchymal Tumours & $\begin{array}{l}\text { Fibromata } \\
\text { Sarcomata }\end{array}$ & $\begin{array}{r}3 \\
20\end{array}$ \\
\hline \multicolumn{2}{|l|}{ Reticulosis } & 11 \\
\hline \multicolumn{2}{|l|}{ Malignant Melanomata } & 3 \\
\hline \multicolumn{2}{|c|}{ Total } & 117 \\
\hline
\end{tabular}

Granulomata may grow during the course of chronic dacryocystitis into polypoid masses, or may follow accidental injury during probing or the retention of a foreign body in the sac. The sequence of events in our case (an attack of sinusitis followed by intermittent epiphora for one year and then by local signs) suggests that some degree of dacryocystitis had preceded the growth of the inflammatory mass and the precipitation of concretions. The case reported by Weizenblatt (1957) occurred after the insertion of a polyethylene tube into a stenosed lacrimal sac for drainage. About 2 years later the tube ends were found to be frayed and thickened and a granulomatous mass almost blocked the lumen. The surface of the mass was bare and epithelium present round the base showed a squamous metaplasia. There was no foreign body reaction although miliary abscesses were present. Weizenblatt considered that the polyethylene tube had undergone a slow process of solution through being exposed for a long time at body temperature to organic acids, enzymes, and purulent secretions. 
Concretions of the Lacrimal Sac.-These are much rarer than calculi in the canaliculi; in both situations these bodies are usually associated with a mycotic infection. Wolter, Stratford, and Harrell (1956) described a case of obstruction to the naso-lacrimal duct caused by a related lesion-a cast that was eventually blown out of the nose and found to be formed of inflammatory exudate in which there were septate hyphae and spores morphologically in keeping with a Candida species. The two earlier cases of Fine and Waring (1947) are similar and Candida albicans was cultured from the one. The absence of demonstrable Streptothrix or other mycotic infection in association with the concretions in our case seems to be unusual.

Intermittent Obstruction of the Lacrimal Sac.-Duke-Elder (1952b) wrote of calculi in the naso-lacrimal sac:

"Such a concretion only occurs in the presence of a chronic dacryocystitis and is usually not diagnosed until operation reveals its presence. An interesting sign is that an intermittent patency may exist, syringing the passage sometimes giving a positive and at other times a negative result (Kofler, 1941); it is as if the stone acts as an intermittent plug as seen in other vesicular organs such as the urinary or gall bladder".

Intermittent epiphora was a symptom in our patient; the mass or the concretions or both may have caused obstruction by acting as an intermittent plug.

\section{Value of Frozen Sections}

A few minutes after part of the mass had been removed a pathological diagnosis was made which clearly determined the extent of the excision necessary. Without a frozen section the lacrimal sac might have been resected with consequent permanent loss of function. The patient had been warned of the possibility of this disaster before the operation, for a carcinoma was considered to be the most likely diagnosis partly because of its relative frequency in this situation. We do not know whether frozen section has been used before to preserve the lacrimal sac by excluding a malignant neoplasm, although it is accepted that biopsy is as a rule the only means of differentiating between the various types of tumour of the naso-lacrimal sac. In addition to preserving the sac, a quick diagnosis by frozen section has the same advantages here as elsewhere in the body: more radical surgery can be done at once if necessary, lessening the chance of blood or lymphatic spread of tumour, and the patient is spared a second operation. A tumour big enough to block the sac is probably always big enough for examination by this technique.

\section{Summary}

A tender naso-lacrimal swelling of 10 days' duration with a history of some recent bleeding from the nostril and epiphora dating from an attack of sinusitis one year previously, was diagnosed as a probable carcinoma. At 
operation the sac was found to be obstructed by a mass, which was shown on frozen section to be inflammatory in nature. Later pathological examination revealed in addition concretions without demonstrable fungal infection. It is possible that the granuloma or concretions or both had produced obstruction by an intermittent ball-valve mechanism. Tumours of the nasolacrimal sac are rare and cannot usually be diagnosed further without biopsy; frozen section has a place in the operative procedure and may allow the sac, which might otherwise be removed on suspicion of malignancy, to be preserved.

The photograph and photomicrographs were made by the Photographic Unit of the South African Institute for Medical Research.

The Director of the South African Institute for Medical Research has given permission for publication.

\section{REFERENCES}

Ashton, N., Choyce, D. P., and Fison, L. G. (1951). Brit. J. Ophthal., 35, 366.

DUKE-ELDER, S. (1952a). "Text-book of Ophthalmology", vol. 5, p. 5345 . Kimpton, London. (1952b). Ibid., vol. 5, p. 5365.

Fine, M., and WARING, W. S. (1947). Arch. Ophthal. (Chicago), 38, 39.

Friedenwald, J. S., and eight others (1952). "Ophthalmic Pathology. An Atlas and Textbook", p. 26. Saunders, Philadelphia and London.

JONES, I. S. (1956). Amer. J. Ophthal., 42, 561.

KOFLER, K. (1941). Klin. Mbl. Augenheilk, 106, 712.

LAUBER, H. (1936). In F. W. von Möllendorf, "Handbuch der mikroskopischen Anatomie des Menschen", Band 3, Teil 2, pp. 597-98. Springer, Berlin.

Maximow, A. A., and Bloom, W. (1957). "A Textbook of Histology", 7th ed., p. 581. Saunders, Philadelphia and London.

SEIDEL, E. (1931). In F. Henke and O. Lubarsch, "Handbuch der speziellen pathologischen Anatomie und Histologie", Band 11, Teil 2, pp. 322-4. Springer, Berlin.

Weizendiatt, S. (1957). A.M.A. Arch. Ophthal., 58, 130.

WolfF, E. (1954). "The Anatomy of the Eye and Orbit", 4th ed., p. 203. Lewis, London.

Wolter, J. R., Stratford, T., and HARrell, E. R. (1956). , A.M.A. Arch. Ophthal., 55, 320. 